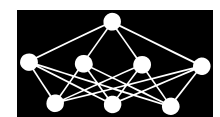

\title{
MODELLING AND OPTIMIZATION OF AN INTELLIGENT ENVIRONMENTAL ENERGY SYSTEM IN AN INTELLIGENT AREA
}

\author{
B. Garlik*
}

\begin{abstract}
The article deals with the current state of energy consumption, the development of distribution networks in the context of its decentralization and integrated community energy systems. The article focuses on the issue and optimization of the operation of EnergyHubs (EH) - energy centres in terms of solving environmental aspects using a mathematical model in the GAMS environment. The acquired knowledge and results of simulations were then applied to a specific urban area to find the optimal variant of EH. The aim of the research is to present its results at the level of cleaner production, improvement of the environment, significant reduction of $\mathrm{CO}^{2}$ and sustainability of society. My experience proves that the achievement of sustainable development goals represents fundamental gaps in research and practical applications, especially at the level of specific projects. It is mainly the application of insufficient indicators and work methodologies in the design of building projects with almost zero energy consumption. Another shortcoming is the coordination of design procedures and applications of optimization and simulation methods necessary to address the energy performance of buildings or clusters of buildings. In addition, the results show growing expectations about the added value of applying artificial intelligence in meeting sustainable development goals, through new data sources that inevitably enter the energy sustainability design process.
\end{abstract}

Key words: energy consumption, passive distribution networks, active distribution networks, integrated community energy system, EnergyHub (EH), energy centre, mathematic model, environmental aspects, GAMS (General Algebraic Modelling System)

Received: November 30, 2020

DOI: $10.14311 / \mathrm{NNW} .2021 .31 .003$

Revised and accepted: February 28, 2021

\section{Introduction}

With increasing energy consumption and efforts to reduce greenhouse gas emissions, the development of renewable energy resources and the reduction of the use of fossil fuels by the European Union, it is necessary to find solutions for energy

\footnotetext{
*Bohumír Garlík; Department of Microenvironmental and Building Services Engineering, Czech Technical University in Prague, Thákurova 7, 16000 Prague 6, Czech Republic, E-mail: bohumir.garlik@fsv.cvut.cz
} 
consumption reduction. Human activity affects the world we live in, and the ability to sustain life is crucial to our future. Environmental science can help to quantify this impact, understand how science affects policy, and how policies affect the environment. Aspects that can significantly affect the environment should not be isolated activities, but they should be part of the organization's projects and processes. It is necessary to use the CSN EN ISO 14031 - Evaluation of Environmental Performance standard and also ČSN EN ISO 14004 - Environmental Management Systems - General Guidelines standard for implementation to determine suitable indicators. The indicators can include, e.g.: electricity consumption, fuel consumption (petrol, diesel, LPG, CNG), tap water consumption, surface water and groundwater consumption, paper consumption, heat consumption for heating, etc. Decentralized energy is a term that is frequently used in promotional materials of foreign and, of course, Czech environmental movements. Applied to electricity, it is - very generally speaking - a transition from the current energy concept based on a limited number of production sources with high installed capacity to a large number of local renewable energy sources (RES) with significantly lower installed capacity, which would produce a comparable amount of electricity, thanks to their a huge number.

This is a process that significantly supports the importance of the meaning of environmental policy in science and its applications. A significant share of small renewable sources enables decentralized energy to significantly reduce emissions of pollutants and greenhouse gases from the assessed options. The application of renewable energy sources (RES) creates unprecedented challenges for regional energy systems to maintain the flexibility and reliability of the system.

Power system operators may limit some of the renewable energy produced at different intervals. From an economic-environmental point of view, the development of sustainable energy must focus on creating a system of:

- Renewable energy sources according to acceptable conditions in the area,

- Application of the best available techniques in the implementation of new sources, so that they include conditions of economic acceptability,

- Energy saving measures in the field of final consumption and primary energy sources with the development of a detailed methodology,

- National action plan for savings (energy efficiency),

- A legislative framework for ensuring sustainable energy development planning with regard to "Environmental Policy" and "Climate Protection Policy".

In this article, I will focus on the above aspects in the context of a proposal based on my research in the field of project creation of the decentralized energy system and thus EH [3].

One of these options is the development of integrated community energy systems and their efficient connection to energy distribution networks. One of the options of effective connection of these community systems to distribution networks is the use of EH or energy centres.

The aim is to analyse the current state of energy consumption, present the available options for the development of distribution systems, use decentralized 
energy sources, summarize the benefits of integrated community energy systems, and especially to introduce EH [4] for possible reduction of energy consumption, efficient use of energy resources and benefits associated with the possibility of the energy conversion between the carriers of these energies.

A significant part of this work, presented briefly in this article, also deals with the mathematical model of EH in the GAMS program, which allows finding of the optimal variant and behaviour of $\mathrm{EH}$ over time, using linear programming. Grid-connected are seen as a way forward in order to increase system flexibility, reduce renewable energy limitations, and increase energy efficiency. In practice, simplified models can significantly affect the performance of grid-connected EH. Therefore, this article proposes a holistic structure to determine the optimal coordinated operation of grid-connected $\mathrm{EH}$ and regional power system by relying on high-performance photovoltaic systems. The level of emissions and the amount of renewable energy applied, together with the total operating costs of the integrated energy system of $\mathrm{EH}$, are among the main objectives of the optimization issue.

The findings are applied in the practical part of this article, where a mathematical model in the GAMS program is used to find the optimal variant of $\mathrm{EH}$ for the given area of M. J. Lermontova - Ve Struhách, Prague 6, Czech Republic.

\section{General model of an Energy Hub}

The future visions of energy networks, including several energy carriers, as multicarrier systems and hybrid systems, allows for greater flexibility in integrated network operation as well as the necessary energy optimization. In fact, different infrastructures can influence each other in terms of energy flow, including their storage, etc. In this case, the so-called EH play a crucial role in the connection points between different infrastructures enabling the flow of energy through different networks. The combination of several converters in these hubs is a necessary motivation for the integration of multiple energy carriers. From this point of view, different support structures can be used by different carriers to provide different forms of energy at the output port. I evaluate the optimization of the energy flow based on the need, e.g. energy consumption costs, emission costs, energy losses, etc., as the basic process of designing a Smart Area environmental system. The state of the system in terms of all control and state variables, including energy flows, is defined by other variables.

I present the EH concept and its modelling, including the optimization of the hybrid electricity system and gas network. The general framework for modelling power systems based on the hub concept is little known at this time. It is a mediumterm management of $\mathrm{EH}$ based on the price of electricity and the uncertainty of solar radiation, which was documented within the application in the EH.

The general model of the EH, presented by Göran Andersson from the Swiss Federal Institute of Technology, can be imagined as seen in Fig. 1. This general model was created for the load, induced especially by a metropolitan area [5].

Decentralized energy source (DES), see Fig. 1, is understood as such a source that is located close to the final consumer and is most often connected to the distribution network of the electricity system. Most of them are small to medium power sources producing power in kilowatts to tens of megawatts. The benefits of 


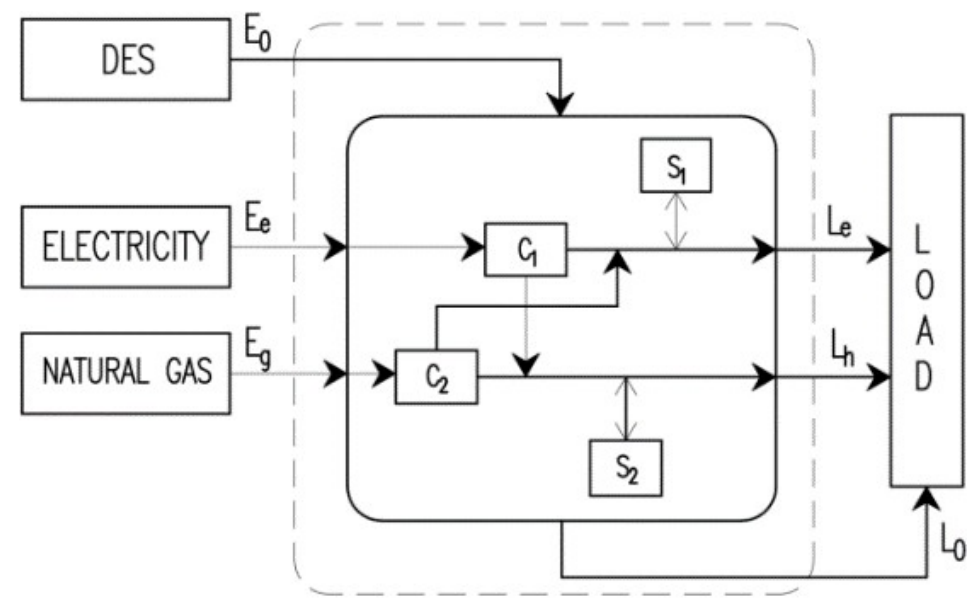

DES - DECENTRALIZED ENERGY SOURCES

Fig. 1 General model of an EnergyHub [5].

decentralized electricity sources are both economic and environmental. In the case of cogeneration units, it is mainly their high efficiency, which can climb up to $95 \%$, which is directly reflected in the savings of primary fuel. For renewable energy sources, their environmental benefits are generally apparent. Decentralized sources also contribute to the safety and reliability of the electricity system. Recently, these smaller sources have been also used in the planning of so-called Smart Grids.

An EH can be considered an object which can convert, regulate and store multiple energy carriers and which represents the interface between different energy infrastructures. In a multi-energy hub, also referred to as $\mathrm{EH}$, various commands are generated within the power flow that meet the output power requirements. A simplified structural diagram of the energy in the EnergyHub is shown in Fig. 1. In Fig. 1, $E_{0}, E_{e}, E_{g}$ represent energy from renewable energy sources (RES), electricity from distribution and natural gas at the input to the $\mathrm{EH}, L_{e}$ a $L_{h}$ represent the electrical and thermal power of the $\mathrm{EH}$ and $L_{0}$ represents the electricity from the RES. On the supply side of the EH, there are electricity, natural gas, and heat, and at the demand side of the user includes the demand for electricity, heat and cold. A coupling matrix model is used to create input carriers that are mapped to the outputs of the EH, as shown in Fig. 3. [10] Furthermore, the conversions $\left(c_{1}, c_{2}\right)$ and storages $\left(s_{1}, s_{2}\right)$ of these energies are included in the model. The basic principle of energy input, conversion, and output by EH can be mathematically expressed by a coupling matrix and graphically represented as seen in (Fig. 2, Fig. 3).

The matrix model in Fig. 3 is used to create input carriers that are mapped to the outputs of the EH, where in Fig. $3 c_{i j}$ is the conversion factor between input and output energy forms, where $0 \leq c_{i j} \leq 1 . E(1, \ldots, m)$ is the input energy (input power) and $L(1, \ldots, n)$ is the output energy (transferred power) from the EH [5]. The EH model is mathematically described in the matrix - vector in Fig. 3. 
Garlík B.: Modelling and optimization of an intelligent environmental...

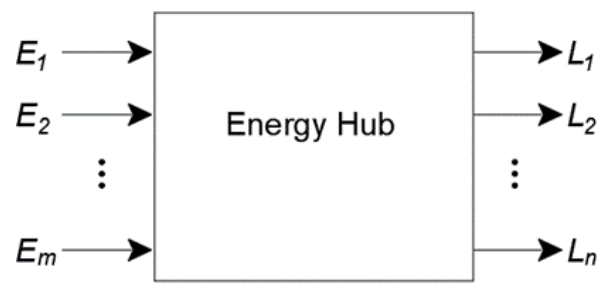

Fig. 2 Inputs and outputs of an EnergyHub [5].

$$
\left[\begin{array}{c}
L_{1} \\
L_{2} \\
\vdots \\
L_{n}
\end{array}\right]=\left[\begin{array}{cccc}
c_{11} & c_{12} & \cdots & c_{1 m} \\
c_{21} & c_{22} & \cdots & c_{2 m} \\
\vdots & \vdots & \ddots & \vdots \\
c_{n 1} & c_{n 2} & \cdots & c_{n m}
\end{array}\right]\left[\begin{array}{c}
E_{1} \\
E_{2} \\
\vdots \\
E_{m}
\end{array}\right]
$$

Fig. 3 Coupling matrix of an EnergyHub [5].

$$
\begin{aligned}
& {\left[E^{\prime}\right]=[\nu] \times[N] \times[L],} \\
& {[L]=[\mu] \times[N] \times[E] .}
\end{aligned}
$$

The energies at the EH input are defined as $E^{\prime}$ see (1) and the output vector of the electricity carrier is defined as $L . \nu$ is a planning factor whose range is $0 \leq \nu \leq 1$. $\mu$ and $N$ are matrices of efficiency of the EH factor schedule.

For subsequent comparison of the EH model with existing traditional energy supply models, the following Fig. 4. Can be used:

Fig. 4(b) shows the supply of electricity only. It is used both to satisfy the demand for heat and for other common consumption such as lighting. Fig. 4(a) shows the supply of both electricity and gas, e.g. supply in areas of suburbs of larger cities, for example, where electricity is used for common consumption and where heat demand is satisfied by burning gas in a gas boiler. Scheme (a) can be mathematically expressed as follows:

$$
\begin{gathered}
E_{e}^{i n}(t)=L_{e} / \eta_{T}, \\
E_{g}^{i n}(t)=L_{g} / \eta_{P K},
\end{gathered}
$$

where $E_{e}^{i n}, E_{g}^{i n}$ is the energy of electricity and the energy of gas at the input, $L_{e}$, $L_{g}$ is the load of electricity and gas at the outlet and $\eta$ is the conversion efficiency. For comparison with traditional energy supply models, the structure of EH can be imagined as shown in Fig. 5.

In $\mathrm{EH}$, various forms of energy are received on input ports connected to the energy infrastructure and energy services in the form of electricity, heating and cooling are delivered on output ports [6]. Within EH, various forms of energy are 


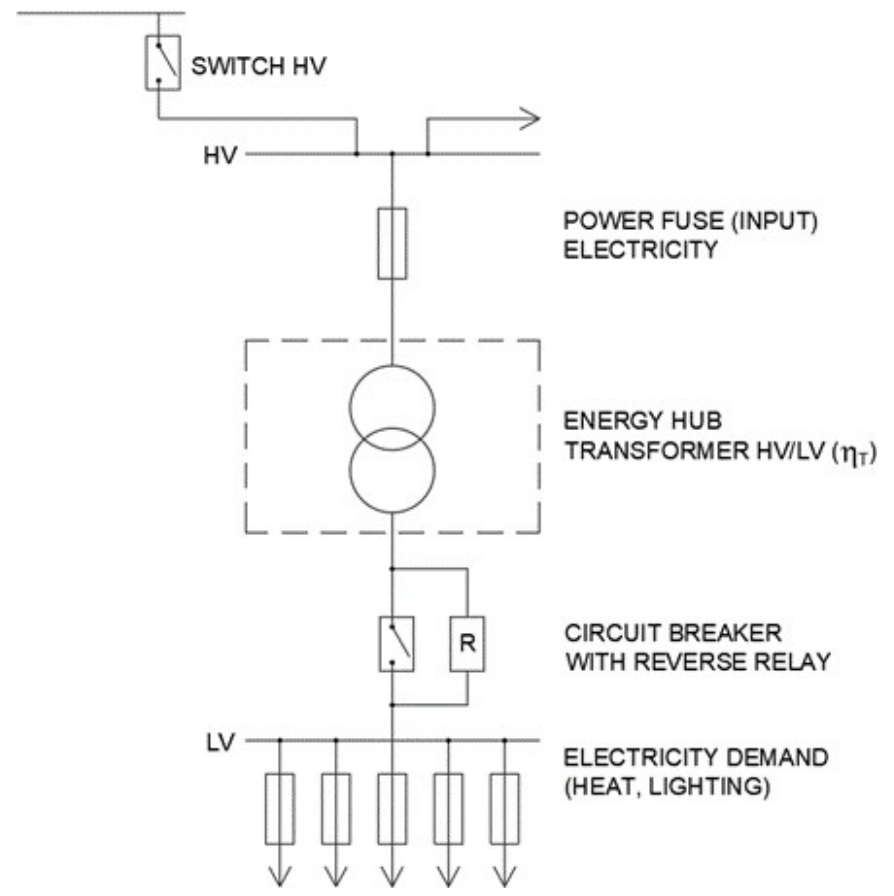

(a)

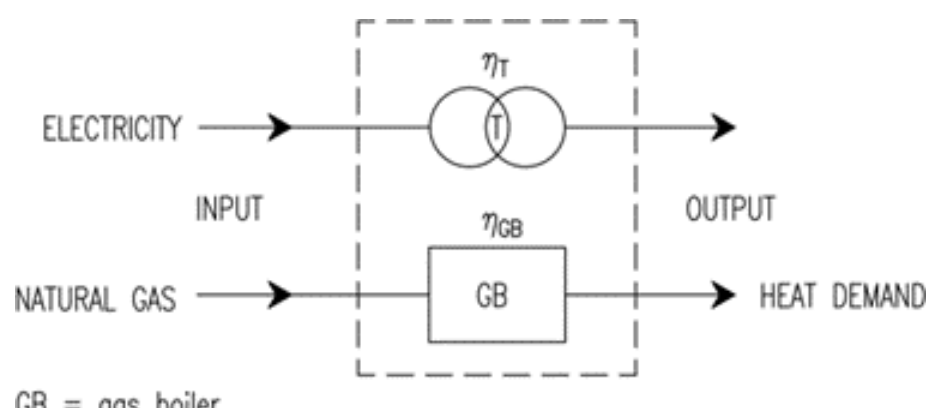

$T=$ transformer

(b)

Fig. 4 Traditional models.

converted and treated using converter technologies such as, Fig. 5: transformers, alternating energy, CHP technology, heat exchangers and absorption chillers. The demand for each type of energy varies considerably during the day and therefore, it is random. Besides, in a competitive electricity market, electricity prices often change over time, thus optimizing.

For one EH input with one output, the coupling factor is the efficiency of the $\mu$ converter. When considering multiple inputs, so-called multi-output systems, the 
Garlík B.: Modelling and optimization of an intelligent environmental...

coupling factor is generally represented as a matrix corresponding to the efficiency of the converter. A planning factor is introduced that determines how the energy at the $\mathrm{EH}$ input is distributed through the converter (conversion), Fig. 5. For simplicity, it is assumed that the efficiency of the transducer is constant, which leads to a constant efficiency of the matrix. In this article (study and subsequent implementation), the planning factor is a variable factor in the operation of a multienergy hub system. The EH optimizes the planning relationship between the input and output energy by adjusting the planning factor.

The EH in Fig. 1 is considered as an example, but energy storage and cooling are not considered. The inputs of the EH are electricity and natural gas and the outputs are electrical load and heat load. Using the law of conservation of energy, the output of the converter is expressed as the product of input and efficiency.

The energy carriers received at the input port of the charge converters are represented as $L_{i}(i=1,2, \ldots, n)$ and the input vector is defined as $E_{i}(i=$ $1,2, \ldots, m) \cdot v$ is the planning factor, the range of which is 0 or 1 and $N$ are the matrices of efficiency and the schedule of EH factors.

$$
\left.\begin{array}{c}
L_{e}(t)-\mu_{C o n v} \cdot P_{w}(t)=L_{e}^{n e t}(t), \\
L_{e}^{n e t}(t)=\mu_{e e}^{T} P_{e}(t)+\nu \mu_{g e}^{G T} P_{g}(t) \\
L_{h}(t)=\left[\nu \mu_{g h}^{G T}+(1-\nu) \mu_{g h}^{F}\right] \cdot P_{g}(t) .
\end{array}\right\}
$$

After setting the relational matrix between the input values and the output load in each $\mathrm{EH}$, the number of input values can be obtained by the following mathematical expression:

$$
\begin{gathered}
{\left[\begin{array}{c}
L_{e}^{n e t}(t) \\
L_{h}(t)
\end{array}\right]-\left[N_{t}\right] \times\left[\begin{array}{c}
P_{e}(t) \\
P_{g}(t)
\end{array}\right]=0,} \\
{\left[\begin{array}{c}
P_{e}(t) \\
P_{g}(t)
\end{array}\right]=\left(\left[N_{t}\right] \times[\mu]\right)^{-1}\left[\begin{array}{c}
L_{e}^{n e t}(t) \\
L_{h}(t)
\end{array}\right] .}
\end{gathered}
$$

In equations (5)-(7) $P_{e}(t)$ and $P_{g}(t)$ represent the input power of natural gas to the $\mathrm{EH}$ at time t; $L_{e}(t)$ and $L_{h}(t)$ represent the user's energy and heat consumption at the given time; $P_{w}(t)$ represents the photovoltaic energy input at time t; $L_{e}^{\text {net }}(t)$ represents the demand for energy that the user needs from $\mathrm{EH} ; \mu_{e e}^{T}, \mu_{g e}^{G T}, \mu_{g h}^{G T}$, and $\mu_{g h}^{F}$ are the conversion efficiencies of the transformer, gas, and electricity in the eventual connection of cogeneration (CHP), as well as the gas for the heat demand in the CHP and the gas boiler in the EH. $P_{w}(t)$ represents the strength of the photovoltaic energy at the time of the curve $t$, which depends on the characteristics of the solar radiation.

Fig. 5 illustrates the different levels of general EH. In EH, various forms of energy are received at the input ports connected to the energy infrastructure and energy services in the form of electricity, heating and cooling are supplied to the output ports [6].

The main advantage of EH is their efficient use of multi-generation (cogeneration, three-generation, poly-generation) systems in order to optimally use energy 


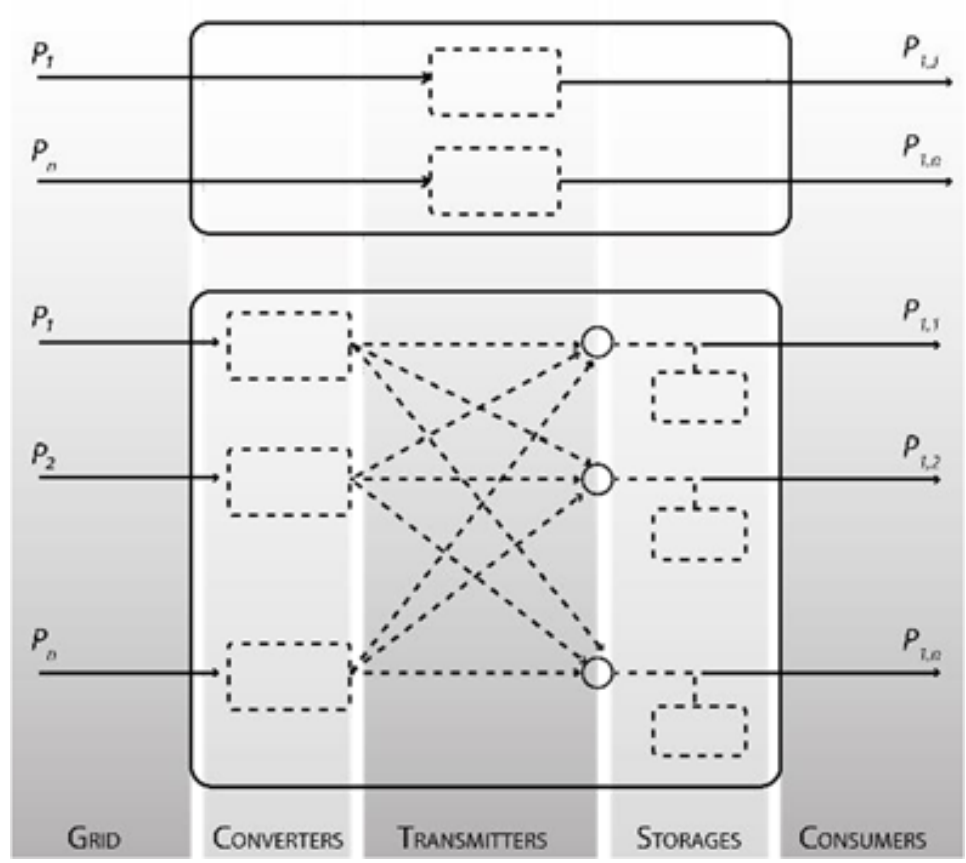

Fig. 5 General structure of an EnergyHub [8].

sources, increase efficiency, and reduce costs and emissions. Although these technological structures are widely used in the available literature, their unambiguous definition has not yet been established in the case of EH. According to academics from the University of Tehran (the capital of Iran), these systems can be called integrated $\mathrm{EH}$ and their definition is as follows: Integrated $\mathrm{EH}$ are multigenerational systems in which different energy carriers are produced, transmitted, stored and consumed to meet different types of demand [3].

$\mathrm{EH}$ have four main functions: energy input, energy conversion (production), energy storage, and energy output. Energy input is represented by: natural gas, liquid fuels (diesel, petrol), wind energy, solar energy, biomass, geothermal energy, energy distribution networks, and industrial waste heat. The conversion components are: transformers, heat exchangers, sorption coolers, electric heaters, and heat pumps.

The Y-type matrix is used to compare three groups of data simultaneously. On the one hand, the matrix diagrams show the interrelationships between the individual items and at the same time demonstrate the possible mutual independence of one item from the others.

Equations and inequalities in the input file are reflected in the output file. Here, these equations are written in the form that GAMS uses for its own calculation unknown on the left, constants on the right. 


\section{Mathematical model of the EnergyHub}

The mathematical model of the $\mathrm{EH}$ is given by the objective evaluation function compiled according to [3], the limitations given by the $\mathrm{EH}$ components and the balance of energy flows through the EnergyHub.

\subsection{Objective function}

The objective evaluation function of the EH mathematical model is based on the prices of input commodities and the daily consumption of these commodities. The criterion for this evaluation function is therefore the sum of the costs of these commodities $[3,11]$.

$$
\min O F=\sum_{t} \lambda_{t}^{a} A_{t}+\lambda_{t}^{b} B_{t}+\cdots+\lambda_{t}^{n} N_{t}
$$

where $\lambda_{t}^{a}, \ldots, \lambda_{t}^{n}$ unit prices of input commodities and $A_{t}, \ldots, N_{t}$ are consumptions of these commodities.

\subsection{Limitations and energy balances}

The amounts of energies, which enter the $\mathrm{EH}$ and which are needed to meet the demand through the conversion, production, or storage of these energies by the EH component are given by the sum of the energies entering the EH components $[3,11]$.

$$
P(t)=\sum_{t} A_{i, t}+A_{j, t}+\cdots+A_{n, t}
$$

where $A_{i, t}, \ldots, A_{n, t}$ is the amount of input energies entering the EH. The amounts of energies at the output of the $\mathrm{EH}$, which are needed in order to meet the demand, are given by the sum of the energies at the output from the EH components [4].

$$
L(t)=\sum_{t} B_{i, t}+B_{j, t}+\cdots+B_{n, t}
$$

where $B_{i, t}, \ldots, B_{n, t}$ is the amount of energies at the output of the EH.

\subsection{Limitations given by the energy supplies by the networks}

The amount of energies entering the EH from distribution networks is limited by the connection capacity of these distribution networks. Alternatively, this limitation is contractually agreed [3].

$$
P_{x}^{\text {net }}(t) \leq P_{x}^{\max }
$$

where $P_{x}^{\text {net }}$ is the immediate amount needed to operate the $\mathrm{EH}$ and $P_{x}^{\max }$ is the capacity of the connection lines [3]. 


\subsection{Limitation of the conversion and production}

The conversion of energies from one form to another, its production or possibly the conversion of energy to its lower level is not lossless. At the same time, the components that enable the conversion or production of energy operate within their operating ranges. Conversion, conversion efficiency, and operating ranges are expressed as follows [3].

$$
\begin{gathered}
B_{t}^{\min }<B_{t}<B_{t}^{\max }, \\
B_{t}=\eta_{x} A_{t} \\
\eta_{x}<1
\end{gathered}
$$

where $B_{t}^{\text {min }}$ is the minimum operating performance of the component, $B_{t}$ is the immediate operating performance of the component and $B_{t}^{\max }$ is the maximum operation performance of the component. Functioning of the components can be expressed as the production of energies $B_{t}$ by the consumption of the input commodity $A_{t}$ with the given efficiency $\eta_{x}$. The primary efficiency $\eta_{x}$ is always lower 1 .

\subsection{Energy storage limitation}

The EH can have three possible types of storage - storage of cold, heat, and electricity. However, in principle, all of these types of storage work in the same way, which can be expressed by the following equations [9].

$$
\begin{gathered}
S O C_{t}=S O C_{t-1}+\left(A_{t} \eta_{a}-\frac{B_{t}}{\eta_{b}}\right) \Delta_{t}, \\
A_{\min } \leq A_{t} \leq A_{\max } \\
B_{\min } \leq B_{t} \leq B_{\max } \\
S O C_{\min } \leq S O C_{t} \leq S O C_{\max } .
\end{gathered}
$$

The $S O C$ variable expresses the state of charge of the storage, $A$ is the amount of energy entering the storage and $B$ represents the amount of energy at the output of the storage. The first equation shows the change in charge level from the previous state with charging efficiency $\eta_{a}$ or discharging efficiency $\eta_{b}$. The limits for charging or discharging the storage are limited by maximum and minimum values, i.e. $A_{\text {min }}$, $A_{\max }, B_{\max }, B_{\max }$, and the storage charge level is defined by the minimum storage capacity value $S O C_{\min }$ and the maximum storage capacity value $S O C_{\max }$.

\subsection{Price of energies (rates)}

The price of energies plays a critical role in the objective evaluation function. It can be constant over time, as in the case of gas prices, or determined by dynamic methods. When determining the price of energies, they are used e.g. for electricity $[4]$. 


\subsection{Optimization}

Optimization to solve practical problems is very widespread in scientific research today and its use has a growing tendency in the field of energies. Recent research on optimizing the EnergyHub operation offers a variety of objective evaluation functions and limitations and it uses various solution tools, including higher-level programming languages such as Delphi, MATLAB, or Fortran. A very widespread higher-level programming language, which has recently been widely used to optimize EH, is GAMS, which uses its built-in algorithms (solvers) that solve the issue of optimal operation of EH.

EnergyHub was investigated from the point of view of a mathematical model and its optimal functioning. This sub-goal was achieved using GAMS software, which allows you to compile, analyze and solve complex mathematical models [6].

The composition of the EH, i.e. its inputs and components, has a great impact on its functioning as a whole. By selecting suitable components and energy resources, it is possible to find the most suitable and optimal variant of the EH to minimize the objective evaluation function based on the given input data of energy demand of the consumers. The aim of EH optimization is to find the most advantageous combination of energy inputs and components of production, conversion, and storage in the $\mathrm{EH}$ to minimize e.g. operating costs or $\mathrm{CO}^{2}$ emissions [3, 4].

\section{General Algebraic Modelling System GAMS}

The general algebraic modelling system is a high-level modelling system for mathematical programming and optimization. It is designed for complex large-scale modelling applications and it allows creation of large, sustainable models that can be quickly adapted to new situations. GAMS allow formulating of mathematical models in a form very close to their mathematical description, but at the same time, the language of the GAMS system is similar to common programming languages. Therefore, it allows mathematical models to be understood and maintained not only by programmers but also by scientists in the field. For a detailed description of the functioning of the mathematical model, a complex variant of the composition of components was chosen.

Fig. 6 shows the component layout of the default EH model [9].

\subsection{Components of the default model of an EnergyHub and mathematical description of their operation}

Battery storage (BS) allows storing of electricity and its subsequent use at the time when it is most needed. This may be the time when there is peak consumption in the network and the immediate consumption of end customers' needs to be covered, or it may also be the time when the hourly rate for electricity is high and the battery storage is sufficiently charged. In this case, the electricity stored in the BS can be used to reduce the consumption of expensive electricity from the distribution network at this time and thus save money associated with its consumption. The BS makes it possible to reduce the costs associated with the consumption of electricity from the distribution network by being able to charge at 


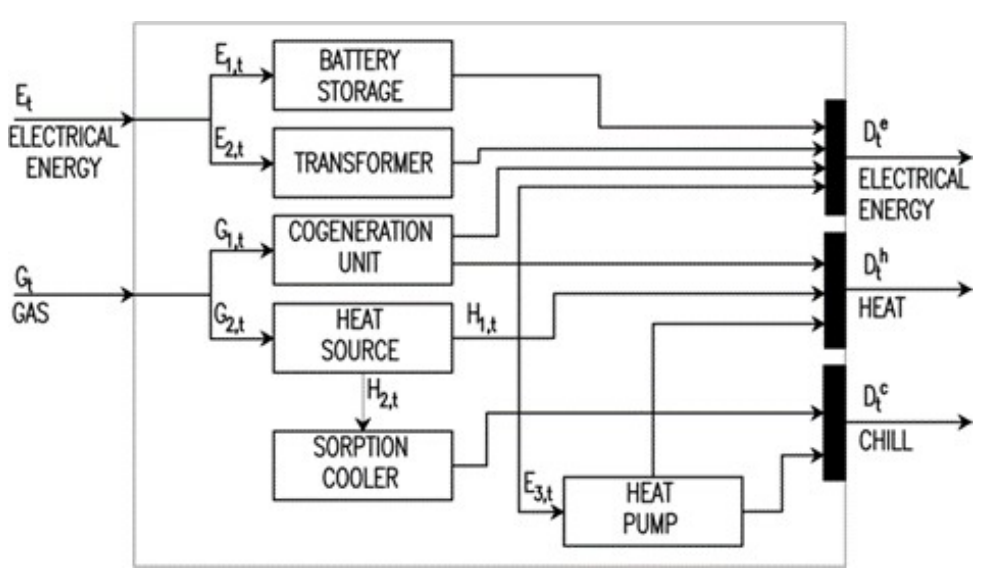

Fig. 6 Default model of an EnergyHub [9].

a time when electricity is cheap and then provide such cheaply charged electricity to customers at a time when direct consumption of electricity from the distribution network would be expensive. The mathematical model of the BS can be expressed as follows [9].

$$
\begin{gathered}
S O C_{t}=S O C_{t-1}+\left(E_{t}^{c h} \eta_{c}-\frac{E_{t}^{d c h}}{\eta_{d}}\right) \Delta_{t}, \\
E_{\min }^{c h} \leq E_{t}^{c h} \leq E_{\max }^{c h}, \\
E_{\min }^{d c h} \leq E_{t}^{d c h} \leq E_{\max }^{d c h}, \\
S O C_{\min } \leq S O C_{t} \leq S O C_{\max }, \\
I_{t}^{d c h}+I_{t}^{c h} \leq 1, \\
I_{t}^{c h} I_{t}^{d c h} \in\{0,1\},
\end{gathered}
$$

where $S O C_{t}$ is the BS state in the given hour, $E_{t}^{c h / d c h}$ expresses the amount of charged or discharged electricity at the given hour and the $I_{t}^{c h}, I_{t}^{d c h}$ variables express whether the BS is charging or discharging at the given hour. The $\eta_{c}$ and $\eta_{d}$ variables express the efficiency of the charging, or discharging of the BS. The $S O C_{\min }$ and $S O C_{\max }$ variables express maximum or minimum capacity of the BS and the $E_{\max }^{c h / d c h}$ and $E_{\min }^{c h / d c h}$ variables express maximum and minimum limits of charging / discharging of the BS.

Transformer For the needs of the mathematical model of the EH, the transformer can be expressed as follows:

$$
E_{t}^{o u t}=\eta_{e e} E_{t}^{i n} .
$$

The conversion of the voltage level is not lossless, therefore it is necessary to introduce the efficiency of the transformer $\eta_{e e} \cdot E_{t}^{\text {out }}$ is the output energy in time and $E_{t}^{i n}$ is the energy at the input of the transformer. 
Cogeneration unit CHP uses primary energy as less polluting energy and provides highly efficient electrical and thermal loads. The current model of combined heat and power generation has been strongly developed around the world. The total capacity is expected to reach $483.7 \mathrm{GW}$ by 2023 [12].

The combined production of electricity and heat can be mathematically described as follows:

$$
\begin{aligned}
& H_{t}=\eta_{g h}^{c h p} G_{t}, \\
& E_{t}=\eta_{g e}^{c h p} G_{t} .
\end{aligned}
$$

The first equation expresses the amount of heat $H_{t}$ produced by the cogeneration unit by burning gas $G_{t}$ with efficiency $\eta_{g h}^{c h p}$. The second equation then expresses the amount of produced electricity $E_{t}$, produced by burning the amount of gas $G_{t}$ with efficiency $\eta_{g h}^{c h p}$.

At a higher level, a combined cooling, heat and energy (CCHP) model was introduced in [13-15] in order to supplement the additional cooling need of an air conditioning system $(\mathrm{AC})$ or an absorption cooler $(\mathrm{ACh})$.

Boiler The process of thermal energy production by burning gas in the boiler is expressed by the following equation:

$$
H_{t}=\eta_{g h} G_{t},
$$

where $H_{t}$ is the amount of thermal energy produced, $\eta_{g h}$ is the boiler efficiency, and $G_{t}$ is the amount of fuel.

Sorption cooler Mathematically, the principle of operation of a sorption cooler can be expressed as follows:

$$
C_{t}=\eta_{h c} H_{t},
$$

where $C_{t}$ is the amount of produced cold, $\eta_{h c}$ is the heat to cold conversion efficiency, and $H_{t}$ is the amount of heat delivered to the cooler.

Heat pump The whole process of operation of the heat pump is mathematically expressed by the following equations:

$$
\begin{gathered}
C_{t}+H_{t}=E_{t} \times C O P, \\
H_{t}^{\min } I_{t}^{h} \leq H_{t} \leq H_{t}^{\max } I_{t}^{h}, \\
C_{t}^{\min } I_{t}^{c} \leq C_{t} \leq C_{t}^{\max } I_{t}^{c}, \\
I_{t}^{c}+I_{t}^{h} \leq 1, \\
I_{t}^{c} \times I_{t}^{h} \in\{0,1\} .
\end{gathered}
$$

The heat pump can operate in either cold or heat production mode. These states are expressed by the $I_{t}^{c}$ or $I_{t}^{h}$ variable. The cooling performance $C_{t}$ or heating performance $H_{t}$ is within the range of the minimum cooling performance $C_{t}^{\min }$ or minimum heating performance $H_{t}^{\min }$ and the maximum cooling performance $C_{t}^{\max }$ or maximum heating performance $H_{t}^{\max }$. 


\subsection{Equation of the mathematical model of the default En- ergyHub}

The mathematical model of the Default EH model is composed of the following equations $[5,9]$.

\section{Objective function}

$$
\min O F=\sum_{t} \lambda_{t}^{e} E_{t}+\lambda_{t}^{g} G_{t}
$$

The resulting value is given by the sum of the consumptions of individual input commodities multiplied by the unit price of these commodities. With the procedure chosen in this way, the most optimal solution is sought by minimizing operating costs - i.e. minimizing the amount paid for the input commodities consumed by the EH [3].

The objective function of the EH model does not have to be based on the financial aspect depending on the amount of input commodities consumed, but it can be based on other various aspects such as emissions of $\mathrm{CO}_{2}$ or other pollutants. In that case, the equation would not include the unit prices of these commodities, but, for example, the amount of $\mathrm{CO}_{2}$ produced per units of commodities consumed. On the left side of the equation, there is the $O F$ variable, which needs to be minimized. On the right side of the equation, there is the sum of the $\lambda_{t}^{e} E_{t}$ and $\lambda_{t}^{g} G_{t}$ products, where $\lambda_{t}^{e}$ is the electricity price, $\lambda_{t}^{g}$ is the gas price, $E_{t}$ is the amount of consumed electricity, and $G_{t}$ is the amount of consumed gas.

\section{Electricity at the EnergyHub input}

$$
E_{t}=E_{1, t}+E_{2, t} .
$$

This equation expresses the balance of electricity flow at the EH input. The total flow of electricity entering the EH $E_{t}$ is the sum of the partial flows of electricity entering the battery storage $E_{1, t}$ and the flow of electricity entering the transformer $E_{2, t}$.

\section{Electricity at the EnergyHub output}

$$
\eta_{e e} E_{2, t}+E_{t}^{d c h}+\eta_{g e} G_{1, t}=D_{t}^{e}+E_{3, t} .
$$

The first term, $\eta_{e e} E_{2, t}$, expresses the flow of electricity through the transformer. The flow of electricity into the transformer is expressed as $E_{2, t}$ and the transformer efficiency is expressed as $\eta_{e e}$. The second term of the left side of the equation, $E_{t}^{d c h}$, is the electricity flow from the BS; this term is non-zero only at the time when it is suitable to use the electricity stored in the BS. The third term on the left side of the equation, $\eta_{g e} G_{1, t}$, expresses the electricity production by the cogeneration unit. $G_{1, t}$ is the gas consumption and $\eta_{g e}$ is the efficiency of gas to electricity conversion by cogeneration unit. On the right side of the equation, there are is a sum of two terms that express the electricity required from the $\mathrm{EH}$. The first term of the right sight, $D_{t}^{e}$, stands for the demand for electricity from the customers connected to the $\mathrm{EH}$ and $E_{3, t}$ expresses the electricity needed for the heat pump operation. 


\section{Input of Electricity to the Battery Storage}

$$
E_{1, t}=E_{t}^{c h} .
$$

This equation assigns a part of the electricity flow entering the $\mathrm{EH} E_{1, t}$ as the electricity flow to the BS $E_{t}^{c h}$.

\section{Status and change of the BS charge}

$$
S O C_{t}=S O C_{t-1}+\left(E_{t}^{c h} \eta_{c}-\frac{E_{t}^{d c h}}{\eta_{d}}\right) \Delta t .
$$

$S O C_{t}$ stands for the current state of charge of the BS at the given time and is given by the sum of the terms on the right side of the equation. The right side of the equation expresses the change in the state of charge of the BS. The $S O C_{t-1}$ term stands for the state of charge of the BS at the previous time. The terms in parentheses describe the process of charging or discharging the BS. The BS charging process is described by the $E_{t}^{c h} \eta_{c}$, term, which expresses the amount of electrical energy that charges the BS. It consists of the $E_{t}^{c h}$, variable, which is the flow of electricity to the BS, and which is adjusted (multiplied in this case) by the efficiency of the BS charging process, $\eta_{c}$. The discharging process is defined by the negative $\frac{E_{t}^{d c h}}{\eta_{d}}$, term, which expresses the amount of electricity, which discharges th BS. The $E_{t}^{d c h}$ variable is the flow of electricity from the BS, which is adjusted (in this case divided) by the efficiency of the BS discharging process, $\eta_{d}$.

\section{BS operating mode}

$$
\begin{gathered}
I_{t}^{d c h}+I_{t}^{c h} \leq 1, \\
I_{t}^{c h} I_{t}^{d c h} \in\{0,1\} .
\end{gathered}
$$

BS has two operating modes - charging or discharging of BS batteries. These modes cannot run at the same time, so the binary variables $I_{t}^{c h}$ and $I_{t}^{d c h}$, are used here. They determine in which mode the BS is currently operating. When the BS is charging, the $I_{t}^{c h}$ value is 1 ; when the BS is not charging, $I_{t}^{c h}$ acquires the value of 0 . The same applies to discharging of the BS. If the BS is discharging, the $I_{t}^{d c h}$ variable acquires the value of 1 , and when the BS is not discharging, the $I_{t}^{d c h}$ variable acquires the value of 0 . This constraint is expressed by the first equation of the above pair, which states that the sum of these variables must be less than or equal to 1 . Since these are binary variables and their value can be only 1 or 0 , there can be no situation where the BS would be both charging and discharging.

\section{Charging Range of the BS}

$$
\begin{aligned}
& E_{\min }^{c h} I_{t}^{c h} \leq E_{t}^{c h} \leq E_{\max }^{c h} I_{t}^{c h}, \\
& E_{\min }^{c h} I_{t}^{c h} \leq E_{t}^{c h} \leq E_{\max }^{c h} I_{t}^{c h} .
\end{aligned}
$$

BS charging is limited by the minimum and maximum value. BS charging, $E_{t}^{c h}$ is limited by the minimum value, $E_{\min }^{c h}$, and by the maximum value, $E_{\max }^{c h}$. The $I_{t}^{c h}$, term, which acquires either the value of 1 or the value of 0 , determines whether or not the BS is charging at the given moment. 


\section{Discharging Range of the BS}

$$
E_{\min }^{d c h} I_{t}^{d c h} \leq E_{t}^{d c h} \leq E_{\max }^{d c h} I_{t}^{d c h}
$$

\section{BS capacity}

$$
S O C_{\min } \leq S O C_{t} \leq S O C_{\max }
$$

$S O C_{\max }$ is the maximum capacity of the $\mathrm{BS}, S O C_{\min }$ specifies the lower limit for battery discharge. The immediate state of charge of the BS batteries, $S O C_{t}$, is between these values, as shown by this equation:

\section{Gas at the EnergyHub input}

$$
G_{t}=G_{1, t}+G_{2, t} .
$$

The gas entering the $\mathrm{EH}, G_{t}$ is the sum of the gas flowing into the cogeneration unit, $G_{1, t}$ and the gas flowing to the gas boiler $G_{2, t}$.

\section{Heat at the EnergyHub input}

$$
\eta_{g h} G_{1, t}+H_{1, t}+H_{t}^{E H P}=D_{t}^{h} .
$$

$D_{t}^{h}$ is the output of thermal energy, $\eta_{g h} G_{1, t}$ expresses the output of thermal energy from the cogeneration unit, where the $\eta_{g h}$ variable is the efficiency of conversion of gas to thermal energy and $G_{1, t}$ is the amount of gas entering the cogeneration unit. The $H_{1, t}$ term is the amount of thermal energy coming out of the gas boiler intended directly to satisfy the demand for thermal energy and the $H_{t}^{E H P}$ term is the amount of thermal energy coming out of the heat pump.

\section{Gas boiler}

$$
\eta_{g h}^{f} G_{2, t}=H_{1, t}+H_{2, t} .
$$

The amount of gas, $G_{2, t}$, is brought to the input of the gas boiler and burned with the efficiency $\eta_{g h}^{f}$ producing thermal energy $H_{1, t}$, which is the consumer's demand for thermal energy and $H_{2, t}$ is the thermal energy intended for the production of cold by the sorption cooler.

\section{Cold at the EnergyHub output}

$$
\eta_{h c} H_{2, t}+C_{t}^{E H P}=D_{t}^{c} .
$$

$D_{t}^{c}$ is the consumer demand for cold from the EH, $\eta_{h c} H_{2, t}$ is the cold output from the sorption cooler. The amount of thermal energy entering the sorption cooler, $H_{2, t}$, is converted to cold with the heat-to-cold conversion efficiency of the sorption cooler, $\eta_{h c}$. The $C_{t}^{E H P}$ term of the equation expresses the cold output from the heat pump. 


\section{Heat pump operating mode}

$$
\begin{gathered}
I_{t}^{c}+I_{t}^{h} \leq 1, \\
I_{t}^{c} I_{t}^{h} \in\{0,1\} .
\end{gathered}
$$

The mode of heat or cold production is expressed by binary variables $I_{t}^{c}$ and $I_{t}^{h}$. These variables acquire values of 1 or 0 , depending on the mode in which the heat pump is operating. To express the operating mode of the heat pump, the first equation of the above two is introduced into the model, which guarantees that the heat pump always operates in only one of these modes at the time, because at the given time, the sum of the binary variables $I_{t}^{c}$ and $I_{t}^{h}$ can only be smaller equal to 1.

\section{Heat pump performance}

$$
C_{t}^{E H P}+H_{t}^{E H P}=E_{3, t} \times C O P .
$$

The amount of produced heat, $H_{t}^{E H P}$, or cold, $C_{t}^{E H P}$ produced by the heat pump is directly proportional to the consumed electricity entering the heat pump, $E_{3, t}$ adjusted by the efficiency of the heat pump, $C O P$, which is the heating factor of the heat pump (Coefficient of Performance).

\section{Heat pump heating performance}

$$
H_{t}^{\min } I_{t}^{h} \leq H_{t}^{E H P} \leq H_{t}^{\max } I_{t}^{h} .
$$

The maximum amount of heat produced by the heat pump is limited by its performance. Limitation of the minimum heat production applies. To apply this limitation, the value of the $H_{t}^{E H P}$ variable is introduced. It expresses the amount of heat produced by the heat pump at the given time. The minimum value of the heat produced is determined by the $H_{t}^{\min }$ variable and the maximum value is determined by the $H_{t}^{\max }$ variable. The $I_{t}^{h}$ term in the equation determines the operating mode of the heat pump at the given time. In the heat production operating mode, when the value of the $I_{t}^{h}$ variable equals to 1 , the $H_{t}^{E H P}$ variable is limited by the $H_{t}^{\min }$ and $H_{t}^{\max }$ variables. When the heat pump is not in the heat production operating mode, the value of the $I_{t}^{h}$ variable equals to 0 and thus the value of the $H_{t}^{E H P}$ variable also equals to zero.

\section{Heat pump cooling performance}

$$
C_{t}^{\min } I_{t}^{c} \leq C_{t}^{E H P} \leq C_{t}^{\max } I_{t}^{c} .
$$

It can be assumed that the heating performance of the heat pump and also the cooling performance of the heat pump are limited. The minimum value of the produced cold is therefore given by the $C_{t}^{\min }$ variable and the maximum value is given by the $C_{t}^{\max }$ variable. The amount of cold produced at the given time, $C_{t}^{E H P}$, is between these two values. The $I_{t}^{c}$ determines whether the heat pump is in the cold production operation mode or not. When the heat pump is in the cold 
production operating mode, the $I_{t}^{c}$ equals to 1 , and the $C_{t}^{E H P}$ variable value is then limited by the values of the $C_{t}^{\min }$ and $C_{t}^{\max }$ variables. When the heat pump is not in the cold production operating mode, the value of the $I_{t}^{c}$ variable equals to 0 and thus the value of the $C_{t}^{E H P}$ variable also equals to zero.

\section{Initial mathematical model of EnergyHub in GAMS}

\subsection{Proposal of the optimal EnergyHub model for a specific area}

The location in Prague (Czech Republic) was chosen for the design of the optimal EH model (Fig. 7). The buildings in this locality were built between 1920 and 1960.

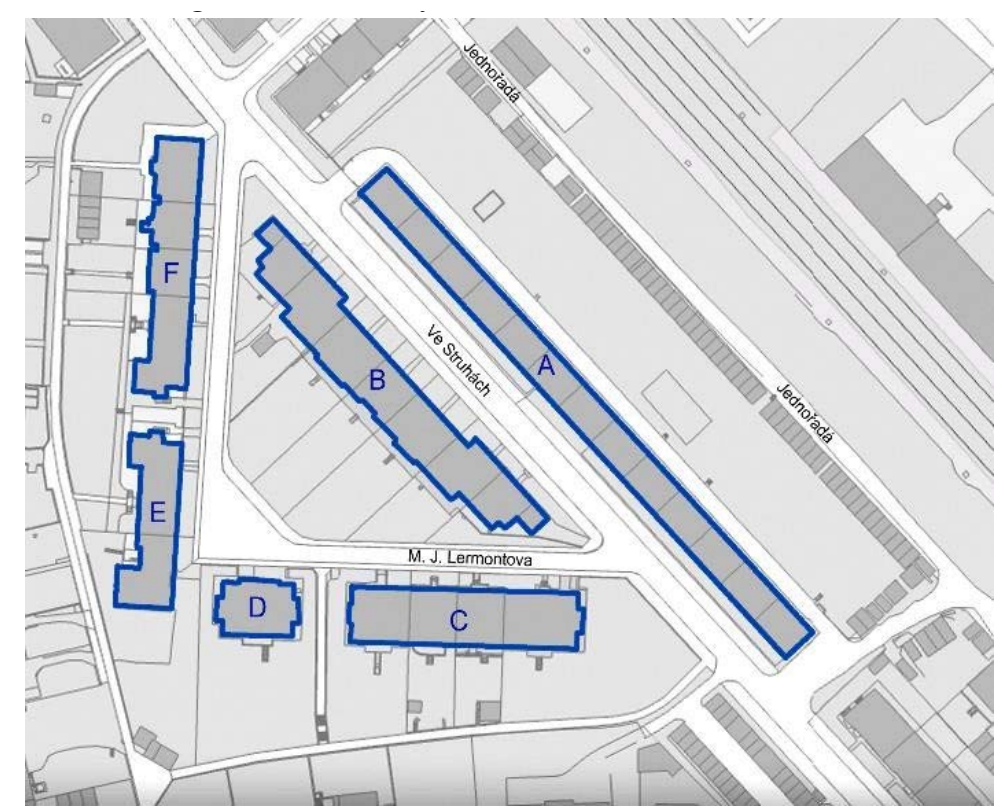

Fig. 7 Layout and buildings in the specified area of Prague.

Hourly heat consumption for heating is determined from the parameters of buildings and temperatures and is summarized in the following Tab. I.

Based on EH Fig. 7, then such a structure makes it possible to satisfy the demand for a specific type of energy in various ways. This leads to improved reliability of energy supply and increased degree of freedom in supply - demand issues. Increasing the degree of freedom on the supply side by the possible use of more energy carriers or components within the EH creates room for possible optimization. EH inputs and components can be characterized on the basis of 
Garlík B.: Modelling and optimization of an intelligent environmental...

price, emissions, availability and other criteria that allow to optimize the use of energy sources and EH components.

\begin{tabular}{|c|c|c|c|c|c|c|}
\hline Building & $\begin{array}{c}\text { Heat } \\
\text { transfer } \\
\text { coefficient } \\
U_{e m} \\
{\left[\mathrm{~W} / \mathrm{m}^{2} \mathrm{~K}\right]}\end{array}$ & $\begin{array}{c}\text { Envelope } \\
\text { area } \\
\\
S \\
{\left[\mathrm{~m}^{2}\right]}\end{array}$ & $\begin{array}{c}\text { Exterior } \\
\text { temperature }\end{array}$ & $\begin{array}{c}\text { Interior } \\
\text { temperature } \\
t_{i} \\
{\left[\mathrm{~m}^{2}\right]}\end{array}$ & $\begin{array}{c}\text { Heat loss } \\
\text { of the } \\
\text { building } \\
Q_{c} \\
{[\mathrm{~W}]}\end{array}$ & $\begin{array}{c}\text { Hourly heat } \\
\text { consumption } \\
\text { for heating } \\
Q_{V Y T, h} \\
{[\mathrm{~kW}]}\end{array}$ \\
\hline A & 1.4 & 1578.6 & -12 & 20 & 70721.28 & 70.72 \\
\hline B & 1.4 & 1072.8 & -12 & 20 & 48061.44 & 48.06 \\
\hline C,D & 1.4 & 422.1 & -12 & 20 & 18910.08 & 18.91 \\
\hline $\mathrm{E}$ & 1.2 & 1182.6 & -12 & 20 & 45411.84 & 45.41 \\
\hline $\mathrm{F}$ & 1.2 & 1182.6 & -12 & 20 & 45411.84 & 45.41 \\
\hline Total & & & & & 228516.48 & 228.51 \\
\hline
\end{tabular}

Tab. I Hourly heat consumption for heating in the area.

\begin{tabular}{cccccc}
\hline Building & $\begin{array}{c}\text { No. } \\
\text { of } \\
\text { flats }\end{array}$ & $\begin{array}{c}\text { No. } \\
\text { of person } \\
\text { per flat }\end{array}$ & $\begin{array}{c}\text { No. } \\
\text { of } \\
\text { pers. }\end{array}$ & $\begin{array}{c}\text { Amount of hot } \\
\text { water per person } \\
\text { per day }\left[\mathrm{m}^{3}\right]\end{array}$ & $\begin{array}{c}\text { Amount of hot } \\
\text { water per day } \\
{\left[\mathrm{m}^{3}\right]}\end{array}$ \\
\hline A & 80 & & 240 & & 19.68 \\
B & 12 & & 36 & & 2.95 \\
C,D & 78 & 3 & 234 & $0.082 \mathrm{~m}^{3}$ & 19.19 \\
E & 112 & & 336 & & 27.55 \\
F & 80 & & 240 & & 19.68 \\
\hline Total & 362 & & 1086 & & 89.05 \\
\hline
\end{tabular}

Tab. II DHW consumption in the given area.

DHW consumption values in the given area are shown in Tab. II, hourly gas consumption is shown in Tab. III and the hourly electricity consumption of the household is shown in Tab. IV.

\subsection{Proposed EnergyHub variants for the given area}

The default EH model needs to be modified for application in local conditions. In contrast to the model described in the theoretical part Fig. 6, there is no demand for cooling and thus it is possible to leave out components or operating states that ensure the supply of cooling from the EH model. Furthermore, there is a demand for gas associated with the EH. This fact must be taken into account in the model. In this paper, five variants of $\mathrm{EH}$ are proposed for the researched area. Variant 1 (V1) of the $\mathrm{EH}$ is connected to the distribution of electricity and gas. At the output, there is a demand for heat, electricity, and gas. Variant 2 is identical to 
Neural Network World 1/2021, 47-76

\begin{tabular}{cccc}
\hline Building & $\begin{array}{c}\text { No. } \\
\text { of } \\
\text { persons }\end{array}$ & $\begin{array}{c}\text { Hourly gas } \\
\text { consumption } \\
\text { per person }\end{array}$ & $\begin{array}{c}\text { Hourly gas } \\
\text { consumption } \\
{[\mathrm{kW}]}\end{array}$ \\
\hline A & 240 & & 4.8 \\
B & 36 & & 0.72 \\
C,D & 234 & $0.02 \mathrm{~kW}$ & 4.68 \\
E & 336 & & 6.72 \\
F & 240 & & 4.8 \\
\hline Total & 1086 & & 21.72 \\
\hline
\end{tabular}

Tab. III Hourly gas consumption.

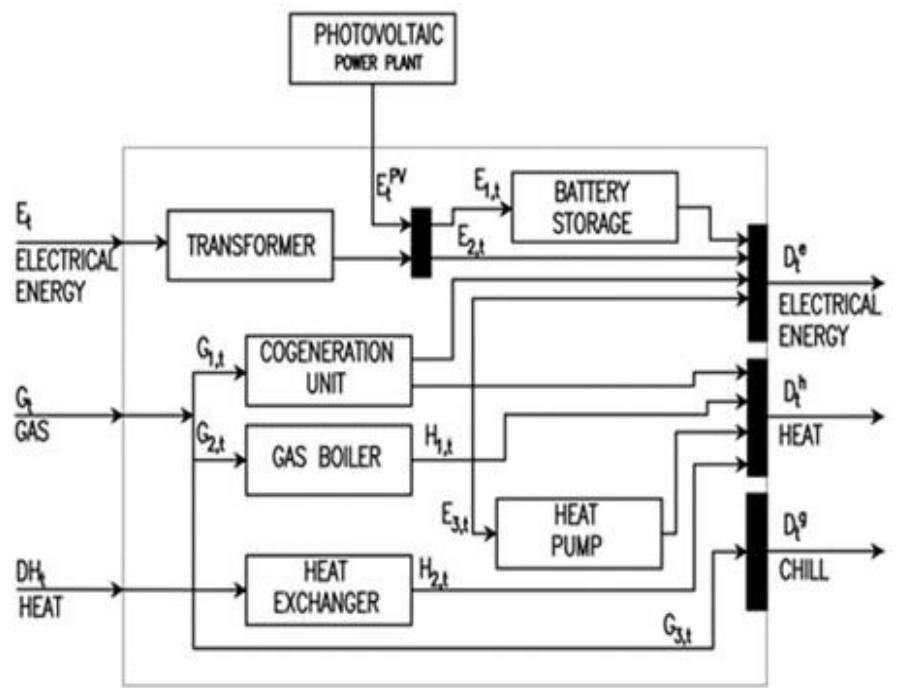

Fig. 8 Variant 5.

$\mathrm{V} 1$ and is supplemented by input from photovoltaic panels (PP). V3 is exploring the possibility of adding BS to V2. V4 is similar to V3, but the demand for heat is ensured by a heat exchanger instead of a gas boiler. V5 is similar to V3 with the possibility of using heat distribution. After the evaluation, Variant 5 is the best suited EH.

\subsubsection{Finding the most optimal variant of EnergyHub using GAMS}

From the obtained data from the given area, prepared mathematical models and other described assumptions, the codes of the GAMS program were compiled to find the most optimal variant of EH. I will briefly introduce the variable codes for Variant 5 in GAMS Alg. 2, i.e. for a given time, creating a table of input data and entering input data for consumption, available power of photovoltaic panels and 
Garlík B.: Modelling and optimization of an intelligent environmental...

\begin{tabular}{cccc}
\hline \multicolumn{3}{c}{ Annual consumption of the household in the block of flats } & $2141 \mathrm{kWh}$ \\
\hline Fig. 7. & TOTAL: & 320 households in Ares \\
\hline Hour & Coefficient & $\begin{array}{c}\text { Sum of } \\
\text { coefficients }\end{array}$ & $\begin{array}{c}\text { Household } \\
\text { consumption }[\mathrm{kW}]\end{array}$ \\
\hline 1 & & & 0.15 \\
2 & 0.268954 & 0.13 \\
3 & 0.2377329 & 0.12 \\
4 & 0.2183508 & 0.12 \\
5 & 0.2414484 & 0.13 \\
6 & 0.2692067 & 0.15 \\
7 & 0.3456215 & 0.19 \\
8 & 0.4094955 & 0.23 \\
9 & 0.4487839 & 0.25 \\
10 & 0.4534914 & 0.25 \\
11 & 0.4741837 & 0.26 \\
12 & 0.4967853 & 0.28 \\
13 & 0.4790129 & 0.27 \\
14 & 0.4378808 & & 0.24 \\
15 & 0.467305 & 0.26 \\
16 & 0.5120402 & 0.28 \\
17 & 0.6165128 & 365.95 & 0.34 \\
18 & 0.73712 & 0.41 \\
19 & 0.7525153 & 0.42 \\
20 & 0.7441204 & 0.41 \\
21 & 0.6907377 & 0.38 \\
22 & 0.5952402 & 0.33 \\
23 & 0.4697944 & 0.26 \\
24 & 0.3530899 & 0.20 \\
\hline & &
\end{tabular}

Tab. IV Hourly electricity consumption in a given area.

hourly price of electricity. Introduction of a variable for the objective evaluation function (8) of the GAMS mathematical model, Alg. 1.

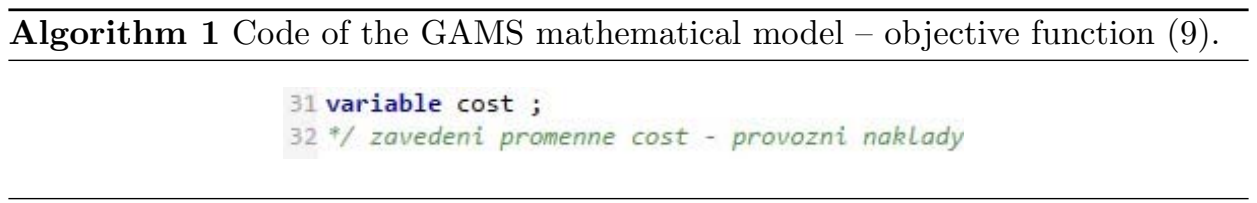

Introduction of a time variable, creation of a table for input data and input of consumption data, available power of the photovoltaic system, and hourly price for electricity Fig. 9.

I will compile the V5 model, including calling of the solver, see Alg. 3. Variants EH 1 to 5 were investigated and optimized in the environment of the mathematical 


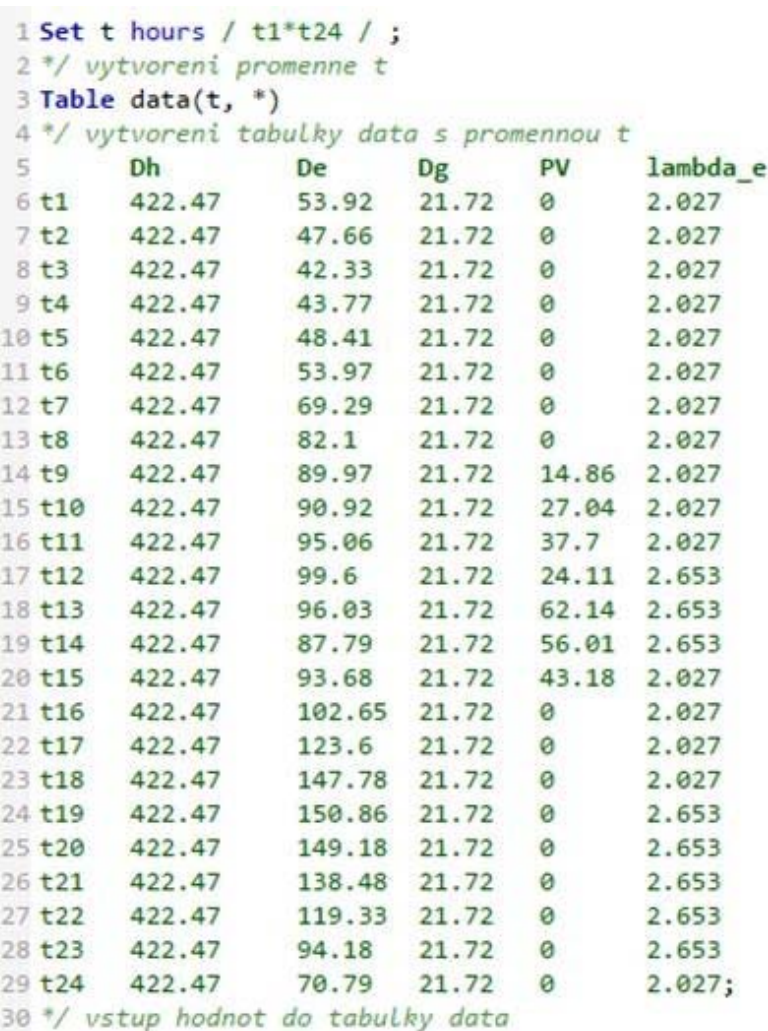

Fig. 9 GAMS code - input data.

model GAMS. The results of research in this area show an economic saving of $51.7 \%$. The results also show the advantages of heat pumps and cogeneration units.

\section{Evaluation of results}

The results for the individual variants of EH are summarized in Tab. V.

\begin{tabular}{cc}
\hline Variant & Value of the objective function \\
\hline Variant 1 & CZK $18,683.95$ \\
Variant 2 & CZK $18,031.56$ \\
Variant 3 & CZK $17,708.92$ \\
Variant 4 & CZK $17,708.92$ \\
Variant 5 & CZK $17,708.92$ \\
\hline
\end{tabular}

Tab. V Summary of individual energy costs of the individual variants. 
Garlík B.: Modelling and optimization of an intelligent environmental...

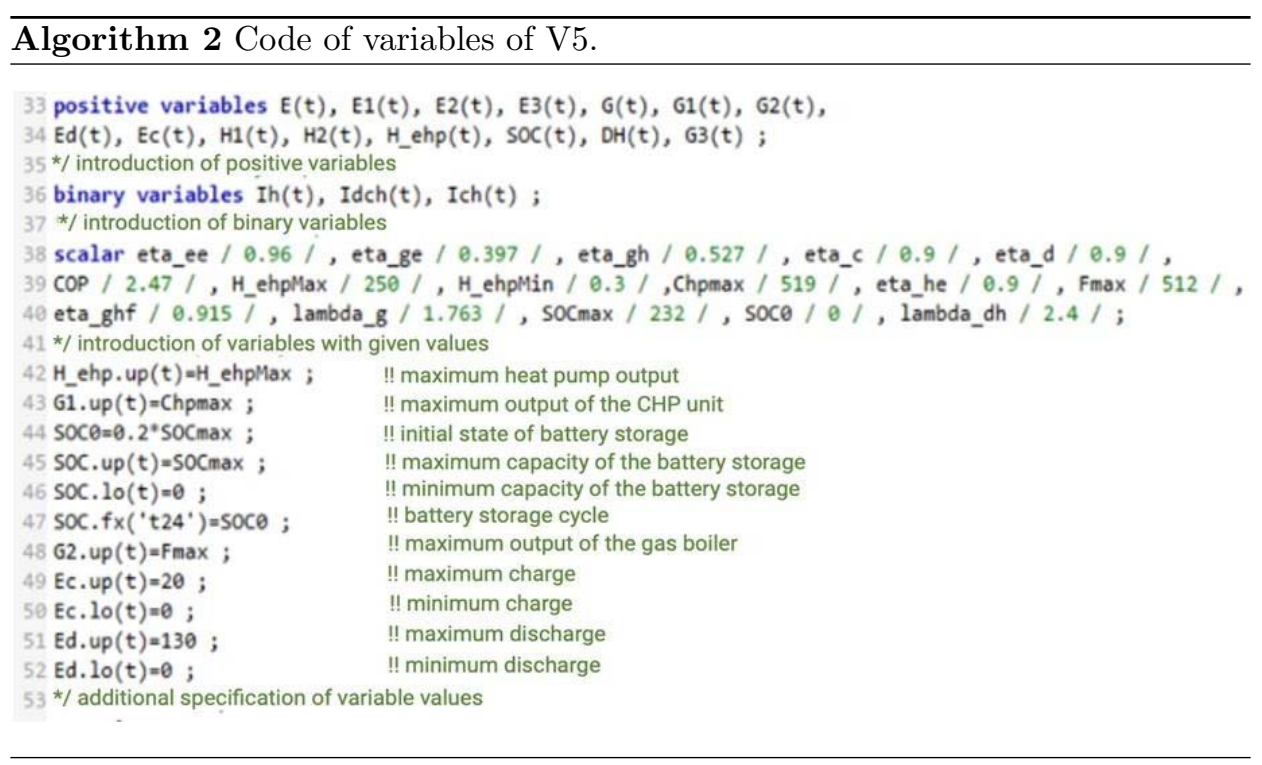

Implementation of the EH model can bring real savings in energy costs compared to the current situation.

Report from the solver for variant 5, see Fig. 10.

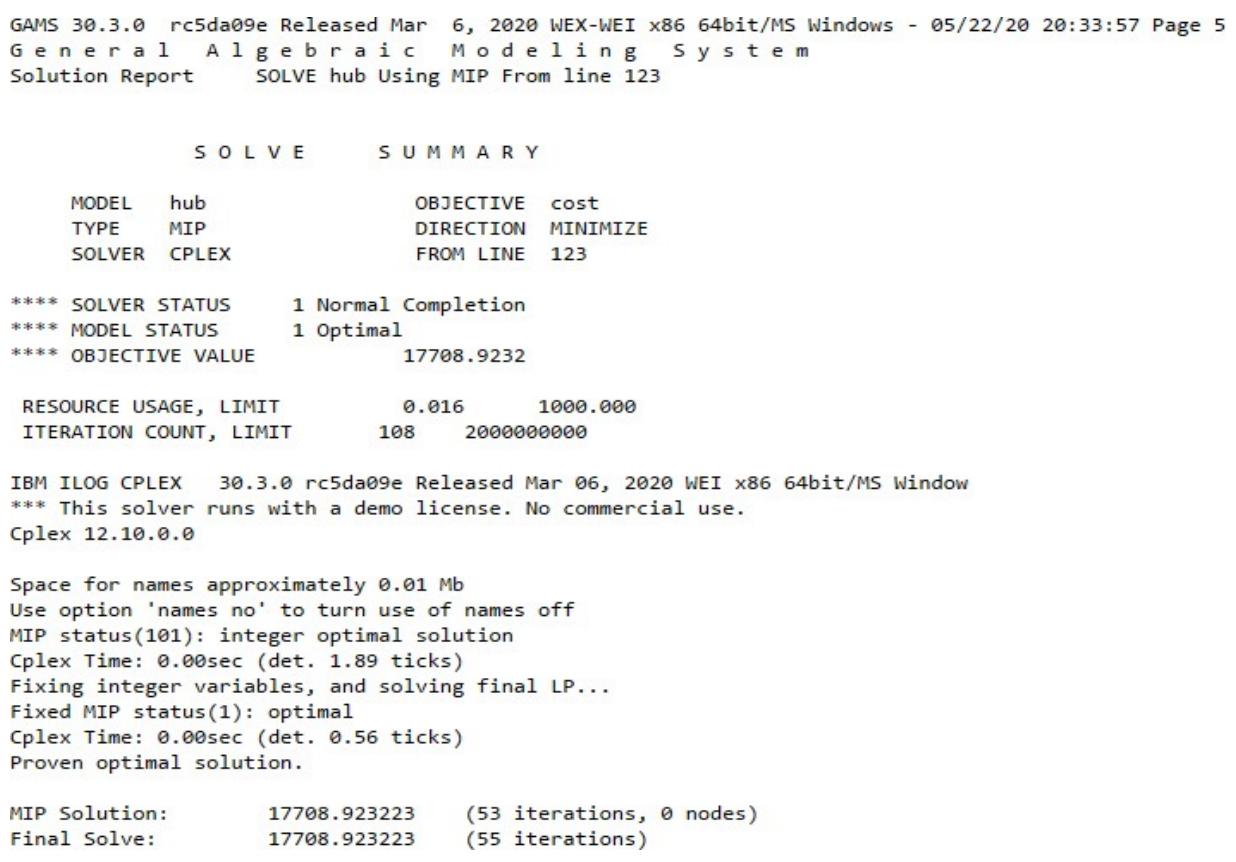

Fig. 10 GAMS - Report of variant 5. 


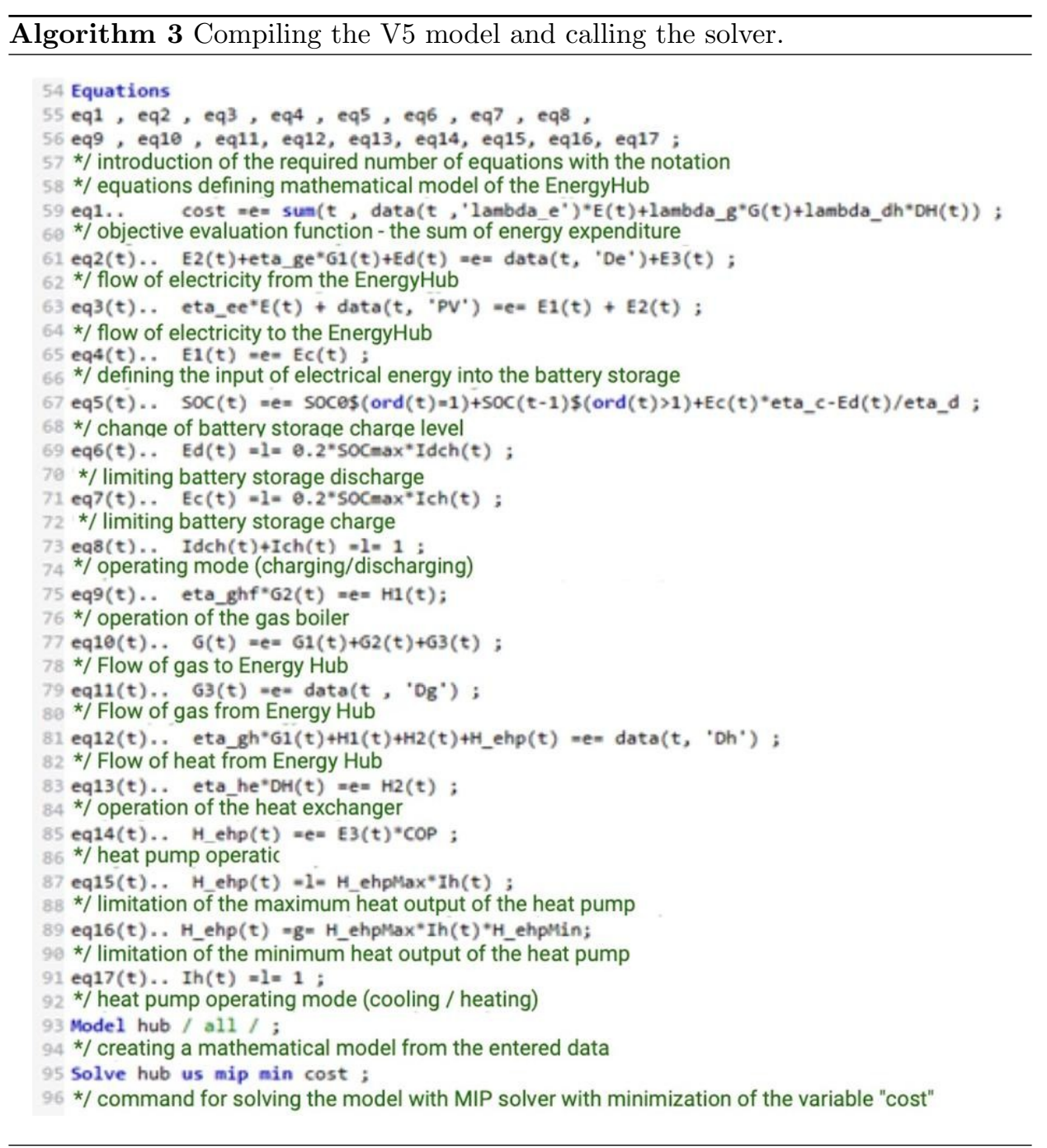

The value of the objective function for variant 5 is: CZK 17,708.92. The daily energy costs of the current state amount to CZK 34,233.57. The most economical variants of the EH model show that the daily energy costs could fall to CZK 17,708.92. So the possible saving is CZK 16,524.65.

The results from the examined area show an economic saving of $51.7 \%$. The results also show the main advantages of heat pumps and cogeneration units. Their high efficiencies and available performance offer great potential for their development. EH was investigated from the point of view of a mathematical model and its optimal functioning. This partial goal was achieved with the help of GAMS software, which represents certain originality in this symbol, which enables the compilation, analysis and solution of complex mathematical models. 
The Chart in Fig. 10 shows the course of electricity consumption from the distribution network $E(t)$, the power supplied by photovoltaic panels $P V(t)$, the production of electricity by the cogeneration unit CHP (Combined Heat and Power) and the electricity entering the battery storage $E 1(t)$. The implementation is evident in Fig. 8.

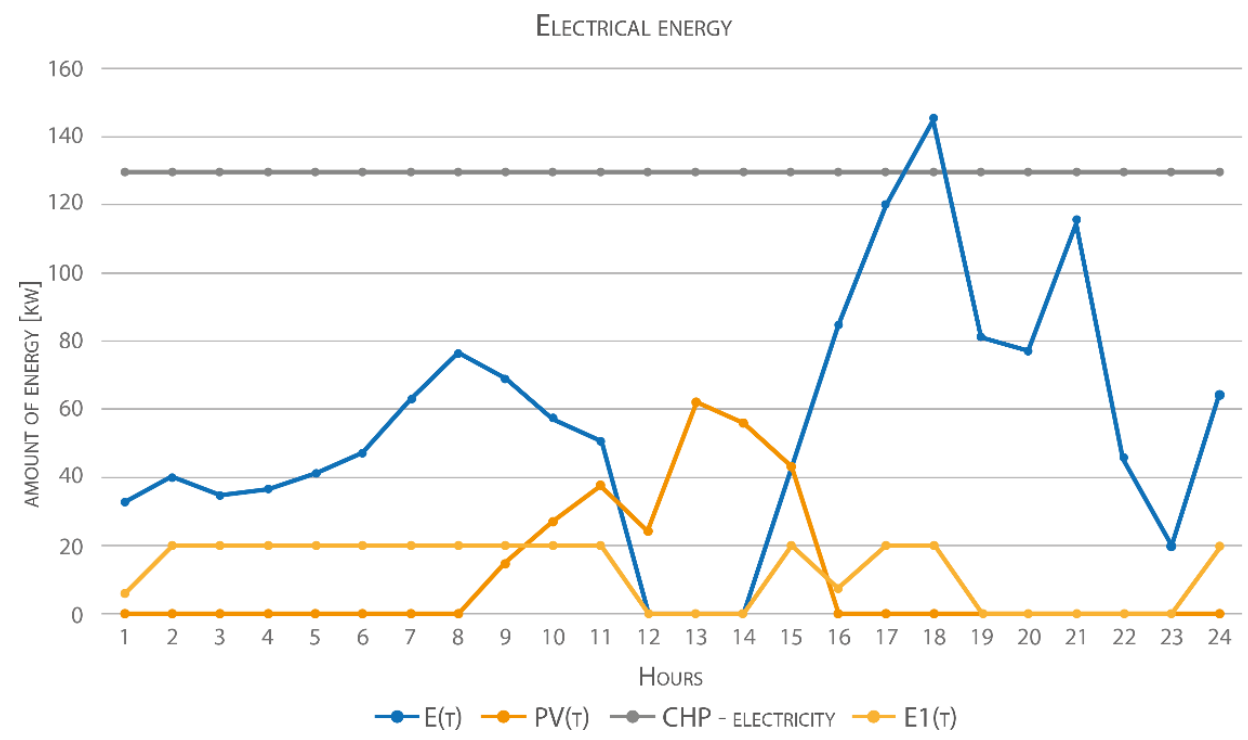

Fig. 11 Electricity - variant 5.

\subsection{Photovoltaic energy, simulation, optimization}

Suggested number of photovoltaic panels based on the building layout in Fig. 7. The essence of the energy concept of the area, Fig. 7, is the interconnection of photovoltaic systems from the whole area (FV1, FV2, FV3, FV4, FV5, FV6) into one large system, including the cogeneration energy system with the power plant in the TS-DS 22 substation $/ 0.4 \mathrm{kV}$; EH see Fig. 8, in the middle of the intelligent area. Such a system responds more flexibly to the current need for electricity in the subbuildings of the cluster of buildings and at the same time provides energy according to the plan for optimizing the allocation of resources directly in the area [3]. This eliminates the problem that would arise with separate systems. In Tab. VI shows the number of photovoltaic panels, their outputs and annual electricity production.

Despite the relatively large roof areas in the area, the space for installing photovoltaic panels is very small: due to the presence of physical obstacles - ventilation shafts, chimneys, lightning conductors, satellite dishes; or placement of buildings in the main directions - the main facades of buildings face north or northeast.

HOMER (Hybrid Optimization Model for Electrical Renewable) is software that is used to simulate and optimize possible combinations of used renewable energy sources and their use. In the case of this project Fig. 12, the simulation results are shown so that the brown color of the column shows the energy, the green color of 
Neural Network World 1/2021, 47-76

\begin{tabular}{cccccccc}
\hline Building & $\begin{array}{c}\text { Roof } \\
\text { area } \\
{\left[\mathrm{m}^{2}\right]}\end{array}$ & $\begin{array}{c}\text { Available } \\
\text { area } \\
{\left[\mathrm{m}^{2}\right]}\end{array}$ & Direction & $\begin{array}{c}\text { Slope } \\
{\left[{ }^{\circ}\right]}\end{array}$ & $\begin{array}{c}\text { Number } \\
\text { of } \\
\text { panels }\end{array}$ & $\begin{array}{c}\text { Output } \\
{[\mathrm{kWp}]}\end{array}$ & $\begin{array}{c}\text { Annual } \\
\text { production } \\
{[\mathrm{kWh}]}\end{array}$ \\
\hline A/FV1 & 888 & 800 & $\mathrm{SV}$ & 30 & 400 & 100 & 95000 \\
$\mathrm{~B} / \mathrm{FV} 2$ & 1215 & 730 & $\mathrm{SV}$ & 15 & 365 & 91.25 & 86688 \\
$\mathrm{C} / \mathrm{FV} 3$ & 850 & 350 & $\mathrm{~S}$ & 15 & 170 & 42.5 & 40375 \\
$\mathrm{D} / \mathrm{FV} 4$ & 265 & 100 & $\mathrm{~S}$ & 15 & 53 & 13.25 & 12588 \\
E/FV5 & 617 & 180 & $\mathrm{~W}$ & 30 & 90 & 22.5 & 21375 \\
F/FV6 & 921 & 285 & $\mathrm{~W}$ & 30 & 142 & 35.5 & 33725 \\
& & & & $\Sigma$ & 1220 & 305 & 289751 \\
\hline
\end{tabular}

Tab. VI Suggested number of PV panels (FV1 to FV6: photovoltaics).

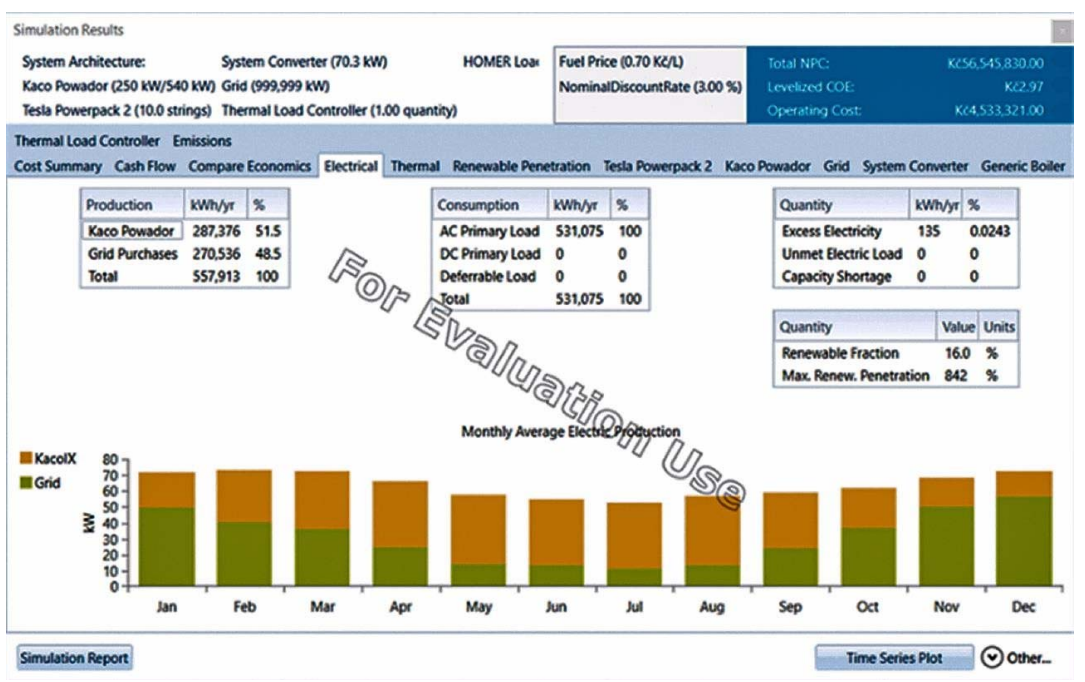

Fig. 12 Simulation results. Yellow $=$ photovoltaic energy, green $=$ grid energy .

the column shows the energy from the network. Therefore, the most advantageous in terms of the use of renewable energy is the use of PVE, cogeneration batteries. In this case, $51.5 \%$ of electricity is covered annually. Fig. 12 shows the importance of the application of a photovoltaic power plant (PPP), ie the consequence of the electrical coverage of the territory in comparison with the electricity from the distribution network.

\section{Evaluation of results}

The results show that the use of a photovoltaic system and battery storage has reduced the daily energy costs of $\mathrm{EH}$. The introduction of the $\mathrm{EH}$ model can bring real savings in energy costs compared to the current situation. 
Thermal and electrical loads were entered for optimization. Furthermore, types of renewable energy sources (PS - photovoltaic system, cogeneration), battery storage, central heat source $\mathrm{DH}_{t}$ and central source of electricity $E_{t}$.

The results for the individual variants of EnergyHubs are summarized in Tab. V. The results show that the use of a photovoltaic system and battery storage has reduced the daily energy costs of EnergyHub. The introduction of the EnergyHub model can bring real savings in energy costs compared to the current situation.

The daily energy costs of the current state amount to CZK 34,233.57; the most economical variants of the EnergyHub model show that the daily energy costs could fall to CZK 17,709.92. So the possible saving is CZK 16,524.65

Variants $3,4,5$ (only described verbally, see Tab. V) have the same daily energy costs due to the fact that the demand for thermal energy is covered mainly by the production of heat from the heat pump. The heating factor of the heat pump, even at such low temperatures, provides sufficient output and thus an economic advantage for the use of the heat pump both in EH and for normal heating and DHW preparation in family houses.

The heat pump works at maximum output throughout the day and the remaining heat energy is produced by a cogeneration unit. It is clear from this that the production of heat by burning gas in a gas boiler or the use of district heat to meet the demand for thermal energy is not economically advantageous compared to the use of heat pumps to cover this demand.

As the heat pump is a very complex device that can be prone to failure, it would be very practical to leave a backup source of heat energy in the EH, either in the form of a gas boiler or a heat exchanger connected to the heat distribution network.

When examining the results, it is also necessary to take into account the fact that these variants are calculated for the most unfavourable day of the year. If other days (such as summer days) were examined, the results would be different. Other possible costs associated with the operation of the EH are also not included; only the energy costs are included in the calculations. The most objective results would be achieved in the case of modelling the operation of $\mathrm{EH}$ variants throughout the year, by including and comparing other costs associated with the operation of EH. However, this is no longer included in this work due to its scope.

Maximizing the use of available RES is an important starting point for the proposed solution. The installation of photovoltaic panels in summer covers up to $80 \%$ of the energy needed for the household.

The conclusion concerning the reduction of emissions, reached in the context of this research and implementation is very important: Based on Tab. VI, the electricity consumption for one household is: $2141 \mathrm{kWh} /$ year. Then the total electricity consumption for 320 households in the specified area according to Fig. 7 is $685,120 \mathrm{kWh} /$ year.

Since the coefficient of contemporaneity at the level of 0.6 must be used according to the Czech standard, then the total electricity consumption in the area is $411,072 \mathrm{kWh} /$ year. The total electricity produced by the photovoltaic system (PVS) installed on the roofs of individual housing clusters in the given area according to Tab. VI is $289,751 \mathrm{kWh} /$ year. 
Due to an estimate of the amount of $\mathrm{CO}^{2}$ (in $\mathrm{kg}$ ) emitted into the atmosphere due to electricity production based on a national energy mix, the emission coefficient was assumed to be $283.6 \mathrm{~g} \mathrm{CO}^{2} / \mathrm{kWh}^{1}$. This leads to the following conclusion:

1. With the electricity consumption in a given area of $411,072 \mathrm{kWh} /$ year, $C O^{2}$ production is equal to 116.58 t of $\mathrm{CO}^{2} /$ year.

2. In case of application of RES installation in the given area, the total consumption of electricity supplied from the distribution network will be at the level of $121,321 \mathrm{kWh} /$ year, which means the production of $\mathrm{CO}^{2}$ would be $34.4 \mathrm{t}$ of $\mathrm{CO}^{2} /$ year.

3. Due to the installation of PVS in the area and its optimal design using $\mathrm{PV}^{*} \mathrm{SOL}$ software, reduction in $\mathrm{CO}^{2}$ emissions by $29.5 \%$ will be achieved.

4. The introduction of the EnergyHub model can bring real savings in energy costs compared to the current situation. The daily energy costs in the given area of the current state amount to $C Z K$ 34,233.57; the most economical variants of the $\mathrm{EH}$ model in Tab. $\mathrm{V}$ show that daily energy costs could fall to CZK 17,708.92. Thus, the possible savings using the most economical variant of the EH model in Tab. V are 16,524.65, i.e. 51.7\%. This corresponds to a reduction in energy consumption using GAMS software optimization.

5. Based on the above calculation and the application of energy sustainability, with a significant reduction in $\mathrm{CO}^{2}$ emissions, a total emission reduction of $81.2 \%$ will be achieved.

The EH was investigated from the point of view of a mathematical model and its optimal functioning. This sub-goal was achieved using GAMS software, which makes it possible to compile, analyse, and solve complex mathematical models. The results also show the main advantages of heat pumps and cogeneration units. Their high efficiencies and available performance offer great potential for their development. The same applies to the installation of PVS in the area.

Recommendations and opinion of the researcher In this research, the EH model is presented with load uncertainties (electricity, heating and cooling) and electricity prices to optimize energy costs. However, renewables with stochastic characteristics and investment costs for equipment are not taken into account. I recommend that the above aspects be further explored in solving the problems of optimal planning and operation for EH.

\footnotetext{
${ }^{1}$ https://ec.europa.eu/environment/emas/pdf/other/ES2016_Consolidated\{\%\}20version_ final_en.pdf;

https://www.svetmobilne.cz/emise-co2-u-elektromobilu-tesla-horsi-nez-bmw/4645-2; https://www.isprambiente.gov.it/files/pubblicazioni/rapporti/R_212_15.pdf (ISPRA 2015)
} 
Garlík B.: Modelling and optimization of an intelligent environmental...

\section{Conclusion}

Our experiment - research addresses the following key issues:

1. The most suitable model of EH variant 5 with different energy load capacity is proposed. Commercial use of large system devices for energy storage using batteries (on-grid) (Battery Energy Storage Systems, hereinafter "BESS") is limited, due to insufficient setting of legal conditions for the operation of such devices in the Czech Republic. The proposed model takes BESS into account to increase operational flexibility and efficiency. This results in improving economic and technical aspects of $\mathrm{EH}$.

2. EH's operational plans shall be optimized while respecting the minimum cost of energy purchased from contractors, taking into account the uncertainties of energy demand and electricity prices.

3. The mathematical model EH represents the uncertainties of the three types of loads (electricity, heating, cooling) and the price of electricity. The results show that the energy flow is optimized in all cases, at the same time the technical requirements for the equipment are ensured. Taking into account uncertainties, demand and total energy purchased from contractors will be reduced. Therefore, the calculation error decreases and the results are more suitable for problems in real conditions.

In my research, the $\mathrm{EH}$ model is presented with load uncertainties (electricity, heating and cooling) and electricity prices to optimize energy costs. Renewable energy sources in our case photovoltaic energy and investment costs for equipment are not taken into account. Then the above aspects should therefore be further explored in the problems of optimal planning and operation for $\mathrm{EH}$.

\section{References}

[1] FAVRE-PERROD P. Vize budoucích energetických sítí. Zahajovací konference a výstava IEEE Power Engineering Society 2005 v Africe Durban, 2005, pp. 13-17.

[2] GEIDL M., KOEPPEL G., FAVRE-PERROD P. Energy Hubs for the future. IEEE Power Energy 5(1), 2007, pp. 24-30.

[3] GARLÍK B. Application of Neural Networks and Evolutionary Algorithms to Solve Energy Optimization and Unit Commitment for a Smart City. Neural Network World, 2018, 28(4), pp. 379-412, doi: 10.14311/NNW.2018.28-017, ISNN 1210-0552.

[4] HA T., ZHANG Y., HAO J., THANG V., LI C., CAI Z. Energy Hub's Structural and Operational Optimization for Minimal Energy Usage Costs in Energy Systems. Energies [online]. 2018, 11(4), [cit. 2020-05-24]. doi: 10.3390/en11040707. ISSN 1996-1073. Available at: http://www.mdpi.com/1996-1073/11/4/707.

[5] THANH-TUNG HA, YONG-JUN ZHANG, JIAN-ANG HUANG, V. THANG. Energy Hub modeling for minimal energy usage cost in residential areas. In: 2016 IEEE International Conference on Power and Renewable Energy (ICPRE) [online]. IEEE, 2016, pp. 659-663 [cit. 2020-05-24]. doi: 10.1109/ICPRE. 2016.7871161. ISBN 978-1-5090-3068-2. Available at: http://ieeexplore.iee.org/document/7871161/

[6] BARMAYOON M.H., FIRUZABAD M.F., GHAHNAVIEH A.R., AGHTAIE M.M. Energy storage in renewable energy centers based on renewable sources, transmission and distribution of IET, 2016, 10(13), pp. 3127-3134. 
[7] THANG V., ZHANG Y., HA T., LIU S. Optimal operation of energy hub in competitive electricity market considering uncertainties. International Journal of Energy and Environmental Engineering [online]. 2018, 9(3), pp. 351-362, [cit. 2020-05-24]. doi: 10.1007/ s40095-018-0274-8. ISSN 2008-9163. Available at: http://link.springer.com/10.1007/ s40095-018-0274-8.

[8] THANG V., ZHANG Y., HA T., LIU S. Optimal operation of energy hub in competitive electricity market considering uncertainties. International Journal of Energy and Environmental Engineering [online]. 2018, 9(3), pp. 351-362 [cit. 2020-05-24]. doi: 10.1007/ s40095-018-0274-8. ISSN 2008-9163. Available at: http://link.springer.com/10.1007/ s40095-018-0274-8.

[9] SOROUDI A. Power System Optimization Modeling in GAMS. První vydání. Cham: Springer International Publishing, 2017. ISBN 978-3-319-62349-8.

[10] GEIDL M., ANDERSSON G. A modeling and optimization approach for multiple energy carrier power flow. In: Proceedings of the 2005 IEEE Russia Power Tech, Saint Petersburg, Russia, 27-30 June, 2005, pp. 1-7.

[11] GARLÍK B. The application of artificial intelligence in the process of optimizing energy consumption in intelligent areas. Neural Network World, 2017, 27(4), pp. 415-446, doi: 10 14311/NNW. 2017.27-023, ISNN 1210-0552.

[12] DARROW K., TIDBALL R., WANG J., HAMPSON A. Kombinované partnerství v oblasti tepla a energie. Americká agentura na ochranu životního prostředí, 2015.

[13] LIU M., SHI Y., FANG F. Combined cooling, heating and energy systems. Restore. Keep. Energy Rev., 2014, (35), pp. 1-22.

[14] FAEZE B., MASOUD H., SHAHRAM J. Optimal control of electrical and thermal energy in a residential energy node, integration of demand response and energy storage system. Building energy, 2015, 90, pp. 65-75.

[15] SHAHAB B., FARAHBAKHSH SAFE, AL: A Financial Approach to the Evaluation of an Optimized Combined Cooling, Heat and Energy System. Energy Power Eng., 2015, 5, pp. 352-362.

[16] THANG V., ZHANG Y., HA T., LIU S. Optimal operation of energy hub in competitive electricity market considering uncertainties. International Journal of Energy and Environmental Engineering [online]. 2018, 9(3), pp. 351-362 [cit. 2020-05-24]. doi: 10.1007/ s40095-018-0274-8. ISSN 2008-9163. 